\title{
Dynamic vs. apparent Redfield ratio in the oceans: A case for 3D-models
}

\author{
Erinst Maier-Reiner \\ Max Planck-Instimu für Meteorologie. Famburg. Germany
}

Received 3 July 1995; revised II December 1995: accepted II December 1995

\begin{abstract}
A three-dimensional model of global biogeochemical cycles (HA.MOCC3) is used to discuss potential explanations for apparent observed deviations from a basin-wide Redfield ratio. Two examples are given in which model information can be taken to close the gaps of incomplete measurements or data aralyses. A third example illustrates how the apparent covariation between phosphate and alkalinity is created by the circulation.
\end{abstract}

\section{Introduction}

The observation that the remnants of remineralization processes are highly correlated in the deep ocean (Redfield, 1934; Takahashi et al., 1985) has strongly influenced our ideas of how the global biogeochemical flux pump operates. Although it is unlikely that a perfect stoichiometric relationship exists between the elementary constituents even within one species, not to mention between different species (Wynne and Rhee, 1986; Nielsen and Tonseth, 1991), the deviations seem to compensate each other in the large scale chemical distributions in the deep sea. In the upper parts of the oceans, however, pronounced deviations from the deep sea chemica: ratios are observed. You and Tomczak (1993) dis-cuss the relationship between oxygen and phosphite in the thermocline waters of the Indian Ocean whyre the ratio apparently is $130: 1$, compared with the deep sea value of 170:1. Sambrotto et al. (1993) reported substantial deviations from the deep sea ratio of $\mathrm{C}: \mathrm{N}$ in the seasonal cycle of productivity. In both pipers $i_{i}$ is concluded that the concept of a constant Redield ratio should be questioned and at least revised, if not abandoned all together.

For global modelling studies (cf. Maier-Reimer. 1993), the assumption of a constant Redfield ratio represents an efficient mechanism to reduce the number of free parameters and, thus, to increase the efficiency of any model prediction. In comparing model results with data on local variations of the geochemical relationships, it is then possible to discriminate between different processes that were not subject to measurements. For such purposes, it is not crucial that the model be fully accurate; as long as the basic structures are reproduced qualitatively, a reliable estimate on the order of magnitude of the neglected processes can be achieved. In this note, I discuss how parts of the observed non-Redfield properties may be explained by confining the discussion to restricted problems, neglecting for the present their part in the global flux system. 
2. Oxygen to phosphate ratio in the Indian Ocean thermocline

Based on water mass analyses on isopycnal surfaces, You and Tomczak (1993) concluded that thermocline waters in the Indiar Ocean seem to be characterised by a phosphate to oxygen Redfield ratio of 1:130, whereas in the deep Pacific and Indian Oceans an almost linear relationship is observed with a slope of 170 moles of oxygen per mole of phosphate. The authors briefly mentioned the potential existence of diapycnal mixing. but ignored it within the framework of their analysis. Motivated by this finding, Anderson and Sarmiento (1995) performed experiments with their nutrient cycling model (Najjar et al., 1992) with different assumptions on the $\mathrm{P}: \mathrm{O}_{2}$ Redfield ratio. In the standard experiment they used a constant value of 170 . In a second experiment, they prescribed explicitly a ratio of 138 in order better to match the observations. That paper illustrates clearly that a model output does not necessarily improve when the model is constrained by additional data. The failure of the second experi- ment to yield any substantial improvement of the reproduction of tracer distributions indicates that some important process which determines the observed slope is overlooked.

A plausible explanation could be that different size classes of the organic debris have different Redfield ratios. Such an hypothesis completely neglects the effects of the ongoing diapycnal mixing of the tracers which have quite different boundary conditions at the sea surface. In this section, I discuss the evolution of an apparent basin-wide Redfield ratio from bottom to top in a three dimensional model of geochemical cycling in the ocean (HAMOCC3; Maier-Re;mer, 1993; abbreviated here as PTD).

The structure of surifice phosphate distribution as a result of the export production (Maier-Reimer, 1993, fig. 2a) is governed by simple MichaelisMenten type of kinetics. The soft tissue products are released downwards with a penetration profile proportional to $\mathrm{z}^{-0.8}$ (Suess, 1980). During remineralization, a constant Redfield ratio of $1: 172$ is assumed. The same ratio is applied for the production

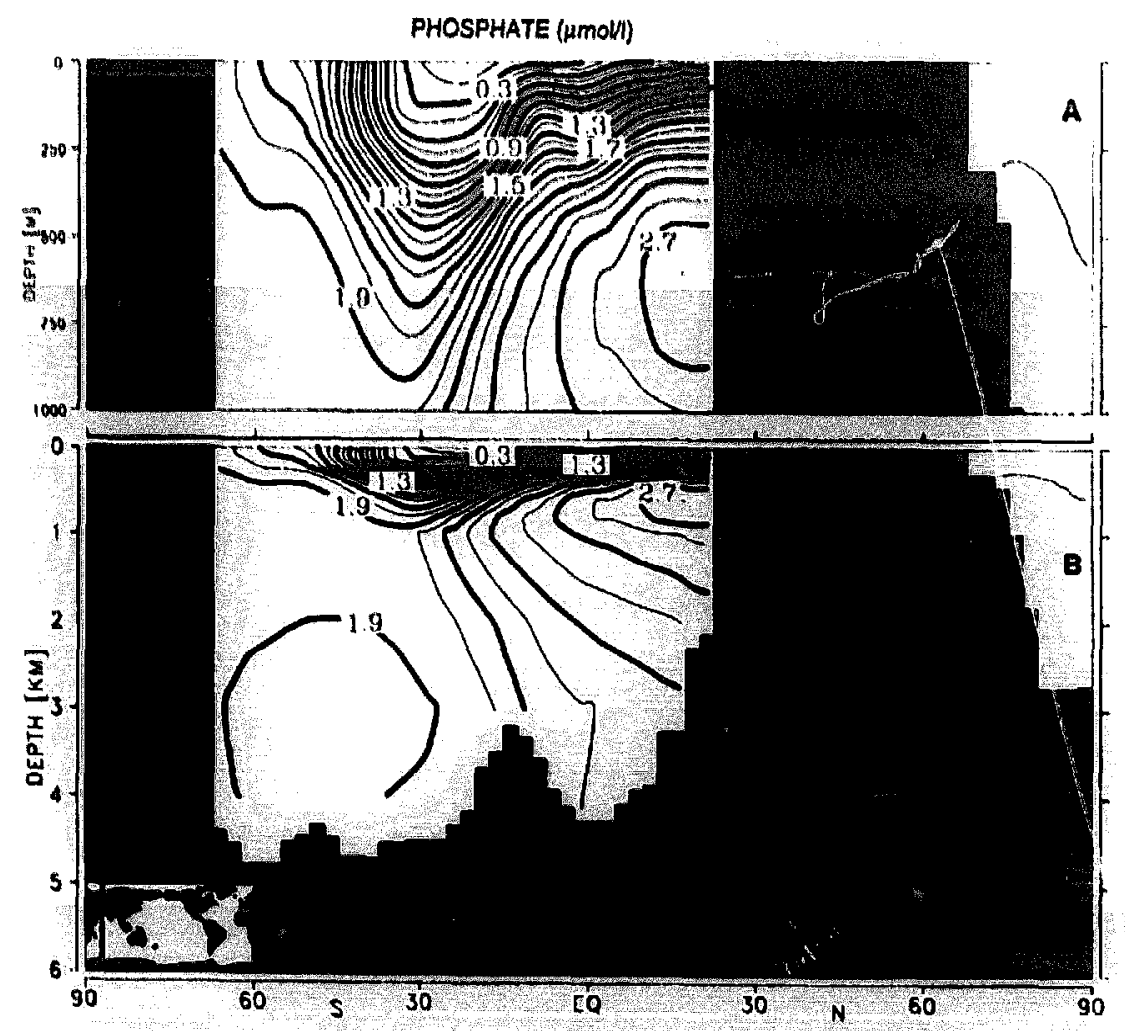

Fig. 1. Distribution of phosphale along a section in the westem Indian Ocean. (A) represents the upper $1000 \mathrm{~m}$ in detail; (B) represents the full depth of the Ocean. The inset shows the position of the transect. 
of oxygen at the sea surface by photosynthesis. There is a resulting covariation of $\mathrm{O}_{2}$ with $\mathrm{PO}_{4}$ to a cuptin of 3km (Maier-Reimer, 1993, fig. 5)

The thermohaline circulation in the Indian Ocean is characterised by a basin-wide upwelling which is fed from Antarctic bottom water and a branch of North Atlantic deep water. It is balanced by an upper layer outflow to the south, yielding a southward heat transport over the entire extent of the Ocean. The mixing of surface properties is enhanced by the strong seasonai fluctuations that are driven by Monsoon cycles.

The simulated phosphate distribution along a section in the westcrn Indian Ocean is illustrated in Fig. 1. The absolute $\mathrm{m}$. um of $2.81 \mu \mathrm{moi} / \mathrm{kg}$ at a uepih of $600 \mathrm{~m}$ evolves from a balance between the prevailing upwelling flux, continual remineralization, and blending with surface waters. For radiocarbon (Fig. 2), the internal sink by decay acts on a much longer time scale, the absolute minimum of $-178 \%$ being at a depth of $2 \mathrm{~km}$.

The covariation of oxygen and phosphate in the Indian Ocean, for a reduced set of grid points (every second in longitude) is illustrated in Fig. 3. The surface values are denoted by " + " and subsurface values warmer than $8^{\circ} \mathrm{C}$ are labelled ..." ", and those colder than $8^{\circ} \mathrm{C}$ by " - ". The subsurface values are restricted to the domain north of $30^{\circ} \mathrm{S}$ since in the mid-latitude subduction zone the water becomes mixed with Antarctic water (You and Tomczak, 1993, based their study on the domain up to $40^{\circ} \mathrm{S}$, but in the southern part the data were extremely sparse). The surface covariation of oxygen with phosphate from the model is dominated by the correlation between warm waters that are poor in oxygen and phosphate, and the cold Antarctic water where both tracers have high incentrations. Obviously, the scatter at the surface is almost perpendicular to the assumed Redfield ratio. However, along the equator, moderately high phosphate concentrations are connected with low oxygen and thus form a separate cluster. The straight lines denote constant values of:

$\mathrm{PO}_{4}^{*}=\mathrm{PO}_{4}+\mathrm{O}_{2} / 172-1.95 \mu \mathrm{mol} / \mathrm{l}$

(Blanton et al., 1991), a modified expression of preformed phosphate which, under the assumption of

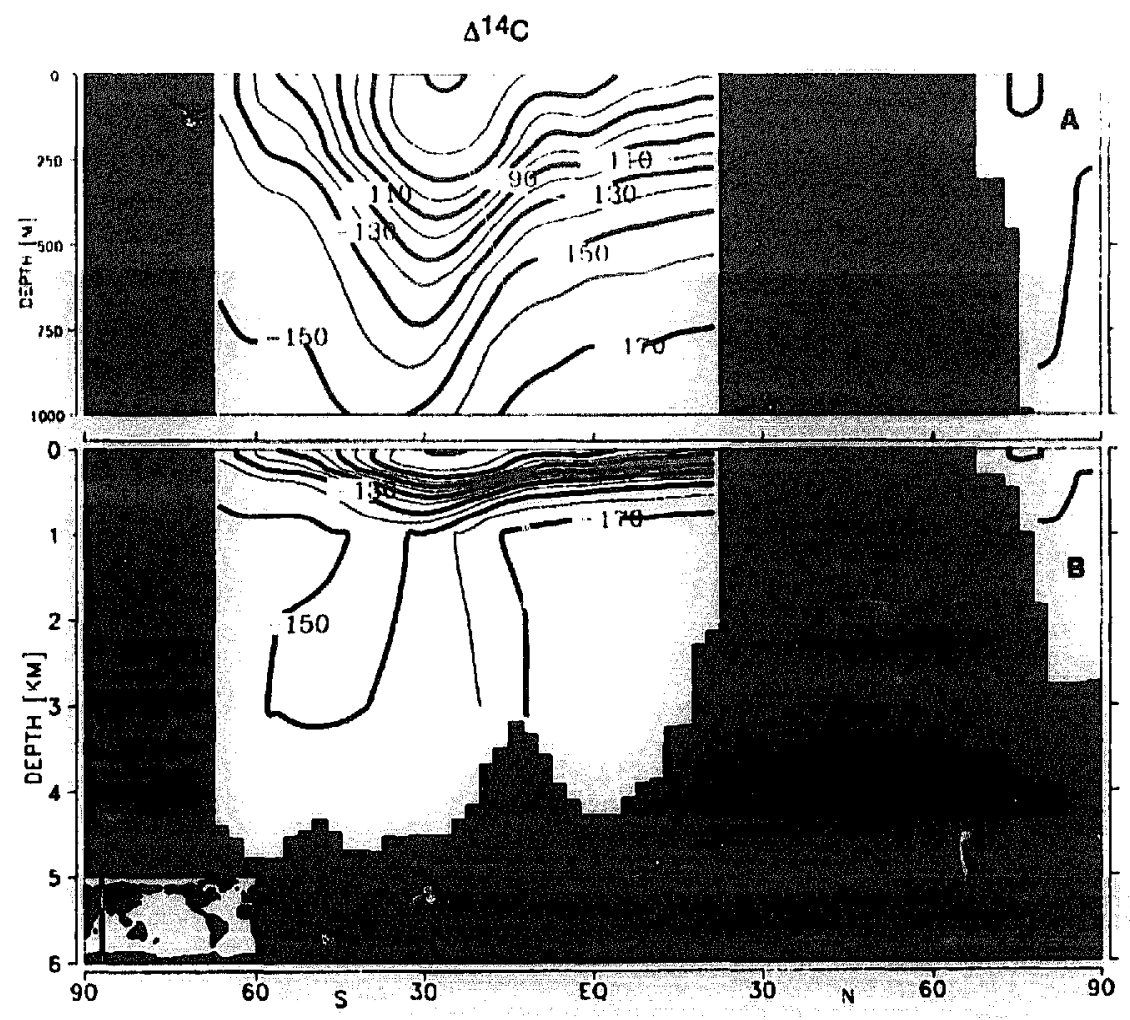

Fig. 2. Distribution of $\Delta^{14} \mathrm{C}$ along a section in the westem Indian Ocean. (A), (B) and inset as Fig. 1. 
a perfect Redfield ratio, should be a conservative tracer in the deep sea. It varies in the deep ocean between 0.7 in the deep Northern Atlantic and 1.7 in the Weddell Sea.

The circulation in this diagram is counter clockwise. The water enters the deep Indian Ocean at $\left(\mathrm{O}_{2}\right.$, $\left.\mathrm{PO}_{4}\right)=(200,2)$. During its northern flow with upwelling it collects the products of remineralization processes, i.e. it undergoes phosphate enrichment and oxygen depletion. From the tropical surface it joins the Antarctic Circumpolar Current $(\mathrm{ACC}$ ) partly by subduction in the Ekman drift convergence and partly by the Agulhas current which is persistently retroflected in the model. Part of the variation in the deep ocean can be explained by blending with North Atlantic Deep Water (NADW) which has a $\mathrm{PO}_{4}^{*}$ of 0.7. In shallower depths, the variation $i$ mostly due to mixing with tropical surface properties. The thick regression line in Fig. 3 for subsurface thermocline water is given by:

$\mathrm{PO}_{4}=2.31-\mathrm{O}_{2} / 125$

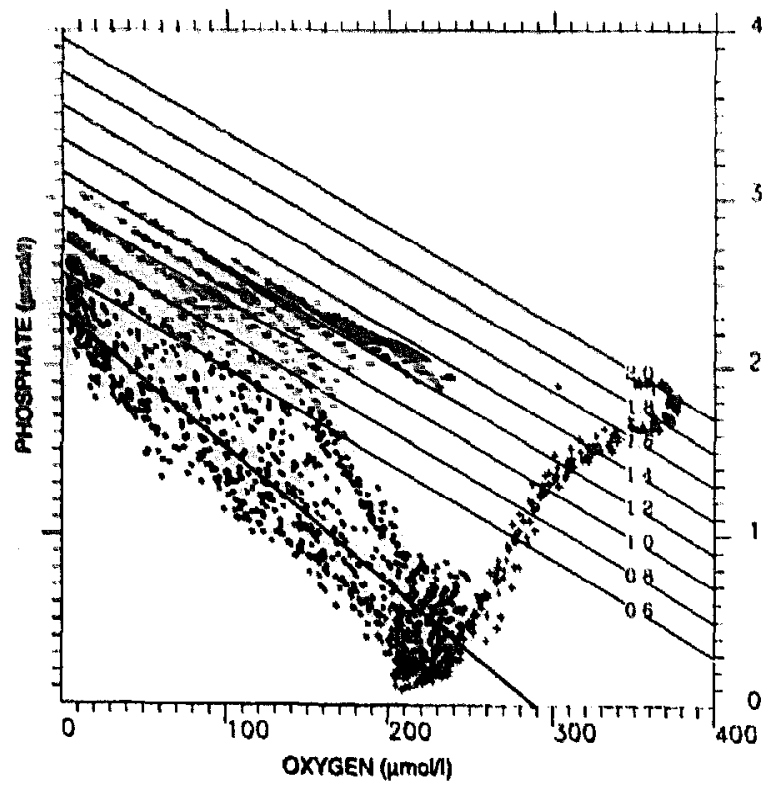

Fig. 3. Covariation of $\mathrm{O}_{2}$ and $\mathrm{PO}_{4}$ in the Indian Ocean. The surfuce values are denoted by "+" subsurface values warmer than $8^{\circ} \mathrm{C}$ are labelled " * ", and " - " denotes values colder than $8^{\circ} \mathrm{C}$. The subsurface values are restricted to the domain north of $30^{\circ} \mathrm{S}$. The circulation in this diagram acts counterclockwise. The thinner straight lines represent constant values of: $\mathbf{P O}_{4}^{-}=\mathrm{PO}_{4}+$ $0_{2} / 172-1.95 \mu \mathrm{mol} / \mathrm{I}$ (see text, p. 115); the thicker straight line represents: $\mathrm{PO}_{4}=2.31-\mathrm{O}_{2} / 125$ (see text, p. 116).
The computed slope depends on the southern boundary of the domain of analysis, i.e. the probability that the water is blended with Antarctic surface water: for $20^{\circ} \mathrm{S}$ it is at 109 , whereas for the equator it is at 95 . It depends also on the temperature range which has to be taken into account. When water bodies with lower temperature are included in the regression, the slope becomes steeper.

\section{Carbon and nutrient fixation in organic pro- duction}

Sambrotto et al. (1993) discussed the covariation between changes of dissolved inorganic carbon and of nitrate in surface waters at several stations for time intervals from weeks to months. After a careful examination of the effects of evaporation/precipitation and formation of calcareous shells by correcting for variations in salinity and alkalinity, they concluded that the $\mathrm{C} / \mathrm{N}$ ratio in marine production should be much higher than thought before. They suggest, therefore, that " the growth of ocean plankton has been underestimated as a sink for atmospheric $\mathrm{CO}_{2}$ ". Without going into the discrimination of potentially different roles of this conjecture for natural and anthropogenic $\mathrm{CO}_{2}$, nor into the problems that may stem from the coexistence of "new" (i.e. nitrate consuming) and "regenerated" (i.e. consuming other nitrogen compounds like ammonia) production, I discuss in this section the potential role of air-to-sea transports of $\mathrm{CO}_{2}$ on the covariation with phosphate. This transport is difficult to estimate from observations since $p \mathrm{CO}_{2}$ and the effective gas exchange coefficient are hard to measure. From measurements, one should compute the flux, $F$, from: $F=k \delta p \mathrm{CO}_{2}$

where $k$ is the gas exchange coefficient and $\delta p \mathrm{CO}_{2}$ is the difference in partial pressure between ocean and atmosphere. From experiments with the PTD model (Maier-Reimer, 1993), however, it was confirmed that the flux is determined primarily by divergences in the ocean and the partial pressure establishes to first order approximation according to:

$$
\delta p \mathrm{CO}_{2}=F / k
$$

Experiments with different formulations of $k$ gave indeed quite different distributions of $\mathrm{pCO}_{2}$, but 


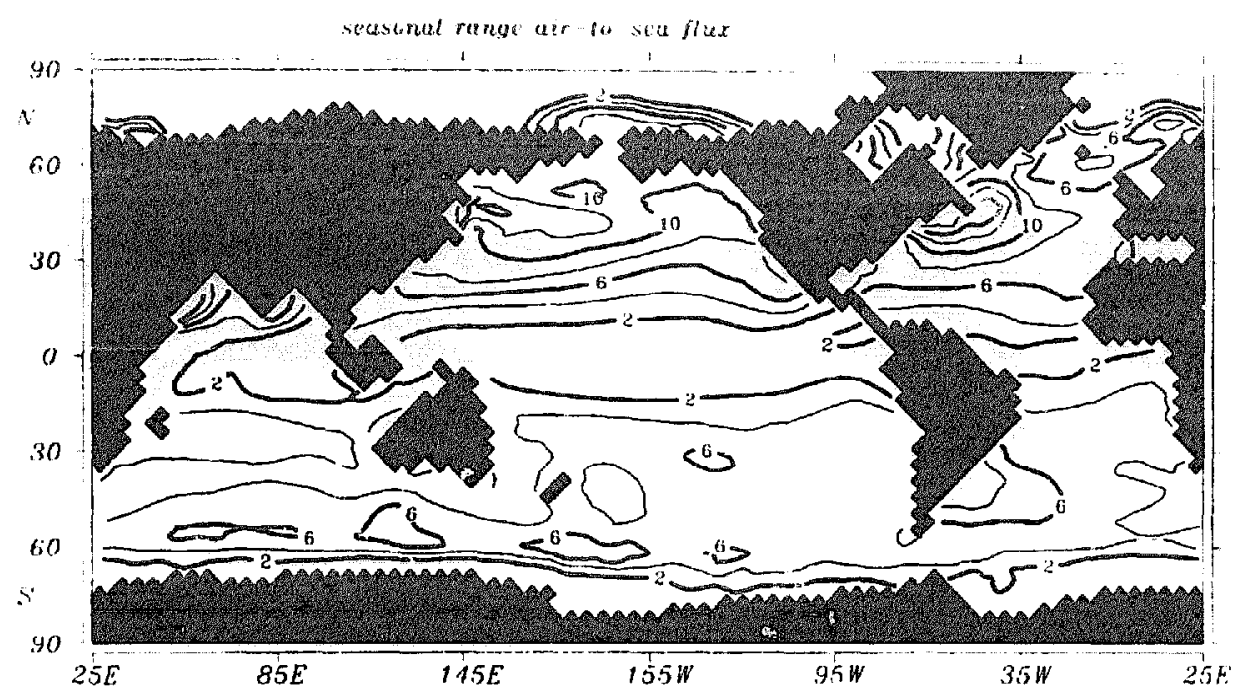

Fig. 4. Seasonal range of global variations of $\mathrm{SCO}_{2}$ induced by gas exchange with the atmosphere. The contour interval is $2.0 \mu \mathrm{mol} 1^{-1}$ month $^{-1}$.

similar distributions of the net air-to-sea flux of $\mathrm{CO}_{2}$. Within the framework of a model, the estimate of the relative importance of the gas transfer is, thus, more robust than from observations. The divergences in the ocean are caused by production and currents. The $p \mathrm{CO}_{2}$ is additionally influenced by temperature. The seasonal effects of production and temperature on the $p \mathrm{CO}_{2}$ are opposite in sign in many parts of the ocean. In spring, the rising temperature tends to cause $\mathrm{CO}_{2}$ release, while rising production tends to remove $\mathrm{CO}_{2}$. It depends on local conditions which one of the two effects dominates. In high latitudes, the switch from unfavourable to favourable conditions for growth occurs rather quickly (Takahashi et al., 1993) and the production effect overrides the thermodynamic effect (in the present form of the PTD model, this feature is not reproduced).

A model of the annual mean $\delta p \mathrm{CO}_{2}$ between ocean and atmosphere is characterised by a strong high in the Equatorial Pacific and moderate lows in

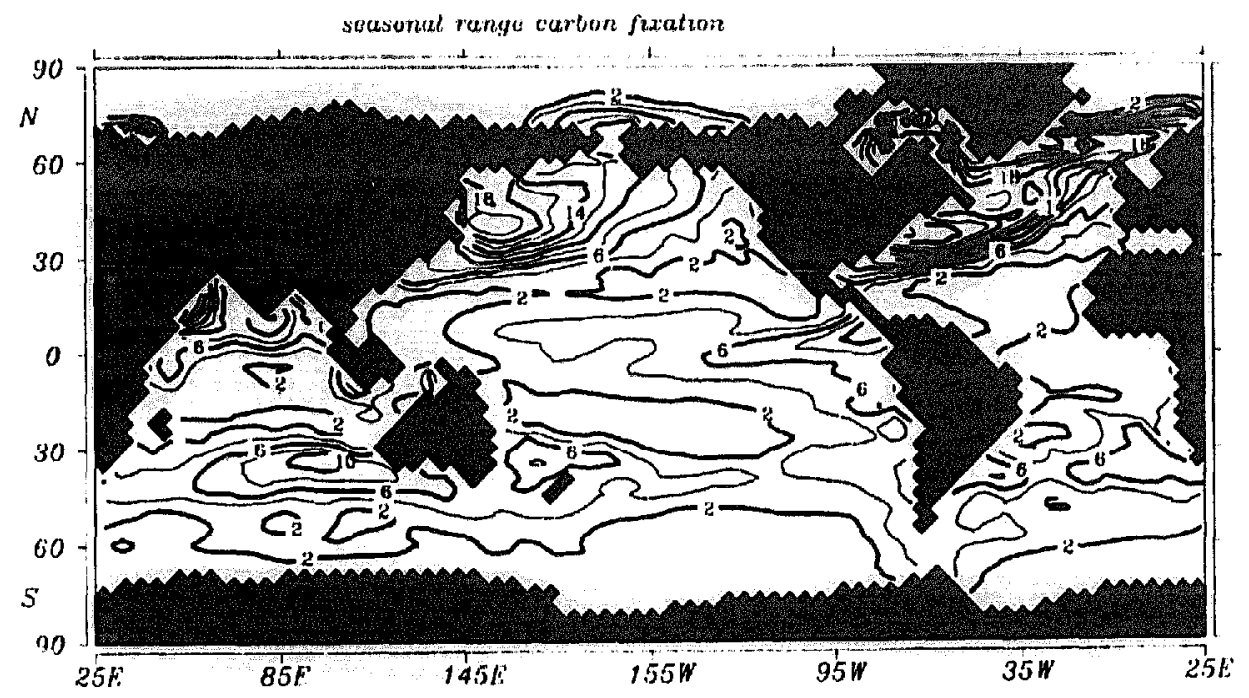

Fig. 5. Seasonal range of global variations of $\mathrm{SCO}_{2}$ induced by fixation into organic material. The contour interval is $2.0 \mu \mathrm{mol} \mathrm{I}^{-1}$ month $^{-1}$. 


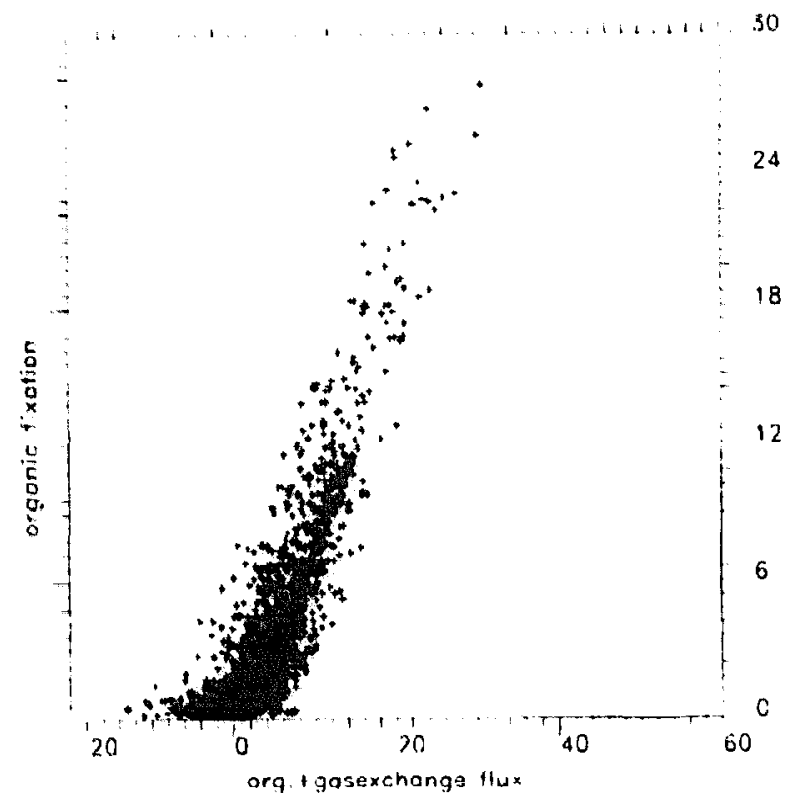

Fig, 6. Covariation of organic fixation and total carbon variations ( $\mu \mathrm{mol}^{-1}$ month ${ }^{-1}$ ) that are not linked with variations of salinity and alkalinity.

high latitudes, especially in the Northern Atlantic (Maier-Reimer, 1993, fig. 11). Below compact sea ice, the gas exchange is blocked and the values are set to zero. The seasonal range $c$ f effective carbon fluxes is shown in Fig. 4. The range is below 2.0 $\mu \mathrm{mol} \mathrm{I}^{-1}$ month $^{-1}$ almost everywhere along the equator and increases towards higher latitudes. The absolute maximum is near Labiador with a range of $12 \mu \mathrm{mol}^{-1}$ month $^{-1}$. The seasonal range of carbon fixation (Fig. 5) looks rather similar and the numbers are comparable. With the assumption of a perfect Redfield ratio, this figure can also be taken as phosphate consumption. For the apparent variations in the sea water chemistry, the phasing between the two fluxes is crucial. The scatter between the sum of the fluxes and the flux by carbon fixation for the Atlantic portion of the model is illustrated in Fig. 6 . There are a few points where the total flux is determined almost exclusively by the high productivity. At low productivities the total flux has both signs. The whole cluster appears to be correlated in a way that total carbon variations are higher than the consumption in organic production. This is due to the parallel nature of the individual fluxes: in summer, the water becomes depleted in $\mathrm{CO}_{2}\left(\mathrm{\Sigma CO}_{2}\right)$ by carbon fixation in organic material, and also by exchange to the atmosphere through the temperature induced $p \mathrm{CO}_{2}$.

\section{Alkalinity variations}

Alkalinity is the key control variable that determines carbon fluxes across the air-to-sea interface. Like salinity, it is modified at the sea surface by precipitation and evaporation. (Since the overall variations are relatively small compared with the mean valuc, this mechanism has a stronger impact on alkalinity than on nutrients or DIC). It is also increased by the production of organic (soft tissue) material due to the incorporation of nitrate, and it is decreased by production of calcareous structures, such as coccoliths. During the remineralization of soft tissue and dissolution of calcite, the reverse changes occur. The strong regional variability of sediment trap data (Tsunogai and Noriki, 199l) makes a global estimate of the relative amounts of the pumps rather uncertain. From the overall gradients of DIC and alkalinity a mean $\mathrm{C}_{\text {org }}: \mathrm{CaCO}_{3}$ relationship of about 4.0 can be derived (Broecker and Peng, 1982), but this estimate is hampered by the uncertainty of thermodynamic influences on DIC. The model yields a global mean ratio of 6.0 and the regional distribution is illustrated in Maier-Reimer (1993, fig. 1d).

The differences of the source/sink terms make the evaluation of scatter diagrams rather problematic. The covariation between alkalinity (normalised with salinity) and phosphate below $1500 \mathrm{~m}$ from the model and from the GEOSECS data (Bainbridge, 1980; Craig et al., 1981) looks like the manifestation of a new Redfield relationship (Fig. 7a), but the sign of the correlation is opposite to the assumed Redfield mechanism which links release of phosphate with consumption of alkalinity. Obviously, the scatter displays primarily the mixing line between North Atlantic deep water from which both are exported and Pacific deep water where both are enriched. The model has a constant set-up of approx. $50 \mu \mathrm{mol}$ $\mathrm{kg}^{-1}$ in alkalinity, but the slope of the regression line is realistically simulated.

The effect of calcite producers on the distribution of alkalinity is easily derived from an experiment with doubled potential for calcite formation and the corresponding $\mathrm{PO}_{4}$ vs alkalinity scatter from such a 


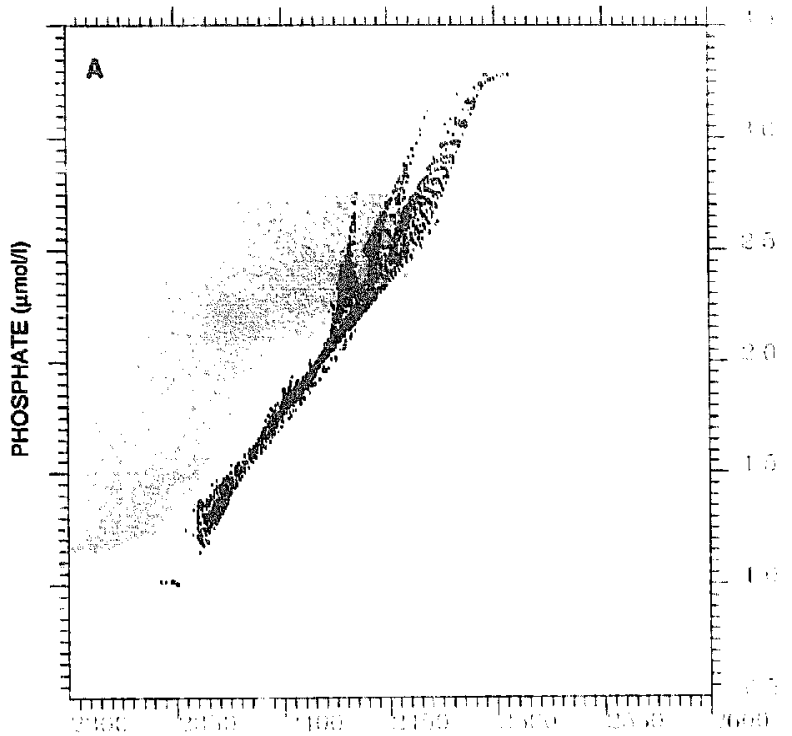

ALKALINITY $(\mu \mathrm{Eq} /)$

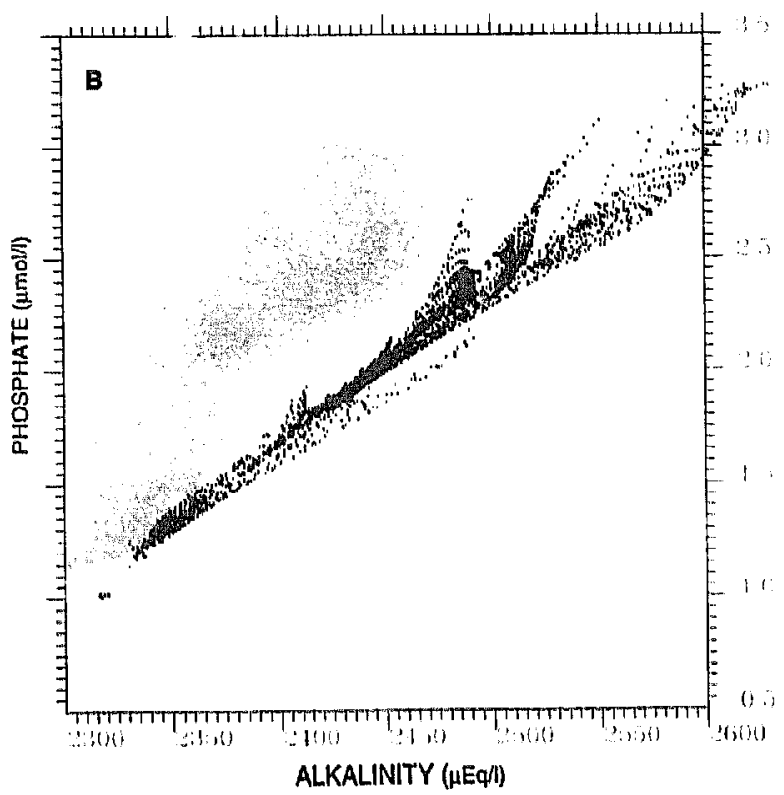

Fig. 7. a. Covariation of alkalinity (salinity normalized) and $\mathrm{PO}_{4}$ helow $1500 \mathrm{~m}$ : GEOSECS data (grey scatter) and model values (dark scatter). The three branches of the model scatter represent the differences between the horizons 2,3 , and $4 \mathrm{~km}$, the highest values lying in the $2 \mathrm{~km}$ layer. b. As (a), but with doubled rate of calcite formation.

run is illustrated in Fig. 7b. The overall variation of alkalinity is also doubled and the depletion in the northern Atlantic is enhanced by about $20 \mu \mathrm{mol}$ $\mathrm{kg}^{-1}$. The comparison between the results shown in Fig. 7a,b indicates that with the assumed penetration profiles, a global mean rain ratio of $6: 1$ for $\mathrm{C}_{\text {org }}: \mathrm{raCO}_{3}$ is more likely than the ratio $3: 1$.

The other changes of simulated marine chemistry from the doubling experiment are rather small. With given inventories of alkalinity and $\mathrm{\Sigma CO}_{2}$, the atmospheric $\mathrm{pCO}_{2}$ is raised by approx. $18 \mathrm{ppm}$. As the doubling acts uniformly, the changes in the structure of air-to-sea flux of $\mathrm{CO}_{2}$ are rather small. The increased export of alkalinity from Atlantic to $\mathrm{Pa}$ cific yields a slight decrease in depth of the lysocline in the Atlantic and a deepening of the lysocline in the Pacific by approx. $1 \mathrm{~km}$.

\section{Conclusion}

It is shown that some observed discrepancies to a globally constant Redfield ratio may be explained by physical processes like mixing and gas transfer. Although far from perfect, models can be taken as a tool for the interpretation of original data. However, modellers should be extremely careful when manipulating chemically active components of Redfield ratios in order to explain observed apparent variations.

\section{Acknowledgements}

Thanks are due to D. Archer, W. Broecker, C. Heinze and K. Six for fruitful discussions. Part of the work was supported by European Commission under contract CT900017. "This is EHUX publication no. 58.

\section{References}

Anderson, L.A. and Sarmiento, J.L., 1995. Glubal ocean phosphate and oxygen simulations. Global Biogeochem. Cycles, in press.

Bainbridge, A., 1980. 1981 GEOSECS Atlantic Expedition; sections and profiles. Natl. Sci. Found., Washington.

Blanton, S., Takahashi, T., Smethie, W. and Ostlund, G., 1991. Radiocarbon decay and oxygen utilization in the deep Atlantic Ocean. Global Biogeochem. Cycles, 5: 87-117.

Broecker, W.S. and Peng. T.H., 1982. Tracers in the Sea. Eldigio Presss, Palisades, NY.

Craig. H., Broecker, W.S. and Spencer, D., 1981. GEOSECS Pacific Expedition; sections and profiles. Natl. Sci. Found., Washington. 
Maier-Reimer, E., 1993. Geochemical cycles in an ocean general circulation model. Preindustrial tracer distributions. Global Biogeochem. Cycles, 7: 645-677.

Najjar, R.G., Sarmiento, J.L. and Toggweiler. J.R., 1992. Downward transport and fate of organic matier in the ocean: Simulations with a general circulation model. Global Biogeochem. Cycles, 6: 45-76.

Nielsen, M.V. and Tonseth, C.P., 1991. Temperature and salinity effect on growth and chemical composition of Gyrodinium aureolum Hulbun in culture. J. Plankton Res., 13:389-398.

Redfield, A.C., 1934. On the proportion of organic derivatives in sea water and their relation to the composition of plankton. In: James Johnstone Memorial Volume. Univ, Liverpool, pp. 176-192.

Sambrolto, R.N., Savidge, G., Robinson, C.. Boyd, P., Takahashi, T., Karl, D.M., Langdon. C., Chipman, D., Marra, J. and Codispoti, L., 1993. Elevated consumption of carbon relative to nitrogen in the surface ocean. Nature, 363: 248-250.

Suess, E., 1980. Particulate organic carbon flux in the oceans- surface productivity and oxygen utilization. Nature, 288: 260263.

Takahashi, T., Broecker, W.S. and Langer, S., 1985. Redfield ratio estimates based on chemical data from isopycnal surfaces. J. Geophys. Res., 90: 5907-5924.

Takahashi, T., Olafson, J., Goddard, J.G., Chipman, D.W. and Sutherland, S.C., 1993. Seasonal variations of $\mathrm{CO}_{2}$ and nutrients in the high-latiude surface oceans: A comparative study. Global Biogeochem. Cycles, 7: 843-878.

Tsunogai, S. and Noriki, S., 1991. Particulate fluxes of carbonate and organic carbon in the ocean. Is the marine biological activity working as a sink of the atmospheric carbon? Tellus, 43B: 256-266.

Wynne, D. and Rhee, G.Y., 1986. Effects of light intensity and quality on the relative $N$ and $P$ requirement (the optimum $N: P$ ratio) of marine planktonic algac. J. Plankton Res., 8: 91-103.

You, Y. and Tomrzak, M., 1993. Thermocline circulation and ventilation in the Indian Ocean derived from water mass analysis. Deep-Sea Res., 40: 13-56. 